\title{
Sperm morphology of Trichospilus diatraeae and Palmistichus elaeisis (Hymenoptera: Chalcidoidea: Eulophidae)
}

\author{
Helen Pinto Santos ${ }^{a}$, Uyra Zama ${ }^{\mathrm{b}}$, Heide Dolder ${ }^{\mathrm{c}}$, José Lino-Neto ${ }^{\mathrm{a}, *}$ \\ a Departamento de Biologia Geral, Universidade Federal de Viçosa-UFV, Minas Gerais, Brazil \\ b Departamento de Ciências Biológicas, Universidade Federal de Ouro Preto-UFOP, Minas Gerais, Brazil \\ ${ }^{c}$ Departamento de Biologia Celular, Universidade Estadual de Campinas-UNICAMP, São Paulo, Brazil
}

\section{A R T I C L E I N F O}

\section{Article history:}

Received 12 December 2012

Received in revised form 12 June 2013

Accepted 15 June 2013

\section{Keywords:}

Spiraled sperm

Ultrastructure

Parasitoid

Insect

\begin{abstract}
A B S T R A C T
In this study, the sperm morphology of the parasitoids Trichospilus diatraeae and Palmistichus elaeisis (Eulophidae) was investigated using light and transmission electron microscopy. In the two species, the sperm are spiral along their entire length and measure about $130 \mu \mathrm{m}$ and $195 \mu \mathrm{m}$ in length, respectively. The head region consists of the acrosome and nucleus. The acrosome is composed of an acrosomal vesicle and, in P. elaeisis, a perforatorium. In both species, an extracellular layer in which several filaments are radiated covers the acrosome and the anterior nuclear region. The nuclei are filled with homogeneous and compact chromatin and measure about $50 \mu \mathrm{m}$ in length in P. elaeisis and $20 \mu \mathrm{m}$ in T. diatraeae. The flagellum consists of an axoneme with the $9+9+2$ microtubule arrangement spiraled in a long helix, two mitochondrial derivatives coiling around the axoneme and, in P. elaeisis, two accessory bodies. In $T$. diatraeae were observed transverse striations throughout the central region of the axoneme, whereas the central pair of microtubules was rarely observed. In the final flagellar region in $T$. diatraeae, different from P. elaeisis, one mitochondrial derivative ends well before the other and both end before the axoneme. The sperm of these two species exhibit features that discriminate one species from each other, as well as characteristics suggest that Eulophidae is closely related to Trichogrammatidae and both of these families are more similar to Eurytomidae than Agaonidae.
\end{abstract}

(c) 2013 Elsevier Ltd. All rights reserved.

\section{Introduction}

The Chalcidoidea comprise up to a third of parasitic Hymenoptera species (LaSalle and Gauld, 1991), forming one of the most abundant groups of insects (Grissel and Schauff, 1997). Although some Chalcidoidea are phytophagous or hyperparasitoids, most are parasitoids of other arthropods, thus playing an important role in controlling the populations of other insects. Therefore, chalcidoids have been successfully used in most biological pest control programs (Greathead, 1986; Neumann et al., 2010; Polaszek et al., 2012).

Despite the economic and ecological importance of this group of insects, knowledge of evolutionary relationships among Chalcidoidea remains unclear, with is no consensus on the placement of several families (Heraty et al., 1997; Munro et al., 2011). Therefore, clear definitions of families based on characters that can be used in cladistic analyses are necessary (Grissel and Schauff, 1997).

\footnotetext{
* Corresponding author at: Departamento de Biologia Geral, Universidade Federal de Viçosa-UFV, Viçosa, Minas Gerais, CEP 36570-000, Brazil. Tel.: +55 31 38993367; fax: +55 3138992549

E-mail address: linoneto@ufv.br (J. Lino-Neto).
}

Authors like Heraty et al. (1997, 2012) drew attention to the use of new classification systems to clarify relationships between families and subfamilies of Chalcidoidea.

In many animal groups, including insects, sperm morphological data have been commonly used in phylogenetic analysis (Carcupino et al., 1995; Dallai and Afzelius, 1995; Dallai et al., 2011; Gottardo et al., 2012; Jamieson, 1987). In this regard, earlier studies have demonstrated that the structural diversity of spermatozoa in Chalcidoidea can provide a system of characters, which may be used in combination with others to study phylogenetic relationships of the group and resolve uncertainty at the family and genus levels.

In this paper we describe the sperm structure and ultrastructure of the parasitoids Trichospilus diatraeae and Palmistichus elaeisis (Chalcidoidea: Eulophidae) to provide spermatological data for future phylogenetic analyses of this insect group.

\section{Materials and methods}

Adult male $T$. diatraeae and $P$. elaeisis were purchased in the department of entomology at the Escola Superior de Agricultura Luiz Queiroz - ESALQ/USP. 


\subsection{Light microscopy}

Seminal vesicles were dissected and squashed on clean glass microscope slides, followed by spreading, then fixed with $4 \%$ paraformaldehyde in $0.1 \mathrm{M}$ phosphate buffer, $\mathrm{pH}$ 7.2. After drying at room temperature, the slides were observed with an Olympus BX41 photomicroscope equipped with a phase contrast lens to allow measurement of the sperm. For nuclei measurements, some slides were stained for $15 \mathrm{~min}$ with $0.2 \mu \mathrm{g} / \mathrm{ml}$ of 4,6-diamino-2phenilidole (DAPI) and viewed with a epifluorescence Olympus BX60 microscope equipped with a BP360-370 nm excitation filter. The images were analyzed using the ImagePro-Plus program.

\subsection{Transmission electron microscopy}

Seminal vesicles were dissected in $0.1 \mathrm{M}$ sodium cacodylate buffer, pH 7.2 and fixed in a $2.5 \%$ glutaraldehyde and $0.2 \%$ picric acid solution with the same buffer, for $24 \mathrm{~h}$ at $4{ }^{\circ} \mathrm{C}$. The material was post-fixed in $1 \%$ osmium tetroxide solution in the same buffer. The material was dehydrated using acetone an embedded in Epon. Ultrathin sections were stained with $2 \%$ uranyl acetate in distilled water and $0.2 \%$ lead citrate in a $1 \mathrm{~N}$ sodium hydroxide solution and observed with a transmission electron microscope, Zeiss Leo 906.

For basic protein detection, the ethanolic phosphotungstic acid method (E-PTA) was applied. Seminal vesicles were fixed only in buffered glutaraldehyde solution for $24 \mathrm{~h}$ at $4{ }^{\circ} \mathrm{C}$. The material was dehydrated in an alcoholic series and treated en bloc by a 2\% PTA solution in absolute alcohol and embedded in Epon.

\section{Results}

The sperm of $P$. elaeisis (Fig. 1A) and T. diatraeae (Fig. 2A) are spiral, long and thin, approximately $195 \mu \mathrm{m}$ and $130 \mu \mathrm{m}$ in length, respectively. They are divided into head and flagellum regions (Fig. 1A and Fig. 2A). The head region consists of the acrosome and nucleus. In both species, the acrosome and the anterior nuclear region are covered by an extracellular layer in which several filaments are radiate (Figs. $1 \mathrm{C}-\mathrm{E}$ and $2 \mathrm{C}-\mathrm{F}$ ). This extracellular layer is longer in the sperm of $T$. diatraeae (Fig. 2C) sperm than P. elaeisis (Fig. 1C), measuring around $2 \mu \mathrm{m}$ and $0.3 \mu \mathrm{m}$, respectively. It in $P$. elaeisis contains two regions, with the inner region being more electron-dense (Fig. 1C). This layer and all the filaments arising from it are E-PTA positive, in both species (Fig. 2F).

The acrosome is very small in both species, measuring around $0.1 \mu \mathrm{m}$ in length. It is composed of an acrosomal vesicle and, in $P$. elaeisis, a rod-shaped perforatorium. This latter has the base inserted into a small cavity at the nuclear tip and is covered by the acrosomal vesicle (Fig. 1C).

In both species the nucleus is filled with homogeneously compacted chromatin (Figs. 1F-H and 2G-J). In P. elaeisis it is long, measuring approximately $50 \mu \mathrm{m}$ in length and $0.2 \mu \mathrm{m}$ at the base, gradually tapering toward the tip (Fig. $1 \mathrm{~A}$ and $\mathrm{B}$ ). In T. diatraeae the nucleus measures $20 \mu \mathrm{m}$ in length and $0.4 \mu \mathrm{m}$ in diameter at the base. It tapers abruptly from base to near half (Fig. 2A and B).

In the transition region of the nucleus-flagellum in both species, the nucleus is connected to the flagellar structures by a centriolar adjunct (Figs. 1F, H, I and 2H-K). The centriolar adjunct overlaps both the base of the nucleus and the axoneme anterior region (centriole). In $P$. elaeisis the overlapped nuclear area is greater than in T. diatraeae (Figs. $1 \mathrm{~F}$ and 2I, however, in T. diatraeae the centriolar adjunct surrounds almost the entire nuclear base (Figs. $1 \mathrm{H}$ and $2 \mathrm{~J}$ ).

The flagellum consists of an axoneme, two mitochondrial derivatives, and in $P$. elaeisis, two accessory bodies (Figs. $1 \mathrm{~J}-\mathrm{M}$ and $2 \mathrm{H}, \mathrm{I}, \mathrm{L}, \mathrm{N}$ ). The axoneme shows a microtubular arrangement of $9+9+2$, nine accessory microtubules, nine peripheral pairs and one central pair (Figs. $1 \mathrm{~N}$ and $2 \mathrm{~N}$ ). However, in T. diatraeae the central pair was difficultly observed (Fig. 2L-O), while transverse striations were observed throughout the central region of the axoneme (Fig. $2 \mathrm{H}, \mathrm{I}, \mathrm{P}$ and $\mathrm{Q}$ ). These striations are compound by dense and pale lines with regular spaces between these ones, measuring among dense lines about $38 \mathrm{~nm}$ (Fig. 2I).

The axoneme is also coiled, so all pairs cannot simultaneously be sectioned at right angles (Figs. $1 \mathrm{M}-\mathrm{P}$ and $2 \mathrm{~L}-\mathrm{O}$ ). At the flagellar posterior end the axoneme is the last to finish, and the accessory microtubules are the first to disappear (Figs. 1O, P and 2L, M). In T. diatraeae sperm, when treated with ethanolic PTA, an EPTA-positive material is clearly observed around and inside the axoneme, but the microtubules are EPTA-negative (Fig. 2F).

The mitochondrial derivatives are arranged in a spiral along the entire axoneme. In cross-section they are oval shaped with equal areas and much smaller than the axoneme (Figs. $1 \mathrm{~L}, \mathrm{M}$ and $2 \mathrm{H}-\mathrm{P}$ ). In the final portion of the flagellum, the mitochondrial derivatives of $P$. elaeisis end approximately together and near the end of the axoneme, since flagella sectioned with only one mitochondrial derivative or just the axoneme rarely are observed (Fig. 1L). In $T$. diatraeae one derivative ends well before the other and both end before the axoneme, because Fig. $2 \mathrm{~L}$ shows various flagella in cross section with only one mitochondrial derivative or only the axoneme.

In P. elaeisis, the accessories bodies are electron-dense, located between the mitochondrial derivatives and the axoneme, and in cross-sections are oval with a very small diameter (Fig. 1J and M). They were not observed in $T$. diatraeae.

\section{Discussion}

The sperm of $P$. elaeisis and $T$. diatraeae exhibit basic morphology similar to that of other Chalcidoidea, for example: (1) spiral sperm; (2) the presence of an extracellular layer coating the acrosome and part of the nucleus from which several filaments are irradiated; (3) the two mitochondrial derivatives have reduced and equal diameters; and (4) at the end of the axoneme, accessory microtubules finish first (Brito et al., 2009; Fiorillo et al., 2008; Lino-Neto et al., 2000; Quicke et al., 1992; Silva, 2010). Meanwhile, there are other features that discriminate these two species of others chalcidoids.

Although the presence of an acrosome is common in Chalcidoidea, its morphology can vary widely. It may be very small, e.g. Mellitobia (Brito et al., 2009), or absent, as in Pegoscapus (Fiorillo et al., 2008). Also, there are species in which the vesicle acrosomal is present but the perfuratorium is not observed, as in Trichogramma pretiosum and Trichogramma dendrolimi (Lino-Neto and Dolder, 2001; Lino-Neto et al., 2000), Mellitobia australica and Mellitobia hawaiiensis (Brito et al., 2009), in Idarnes sp.1 and sp.2 (Silva, 2010) and in $T$. diatraeae studied here. Likewise, the extracellular layer was not observed in some chalcidoids as, for example, Idarnes sp. 1 and sp.3 (Silva, 2010). However, this layer, with filaments radiating from it, is not unique to chalcidoids, as observed in Ichneumonoidea (Moreira et al., 2010; Quicke et al., 1992) and Cynipoidae (Newman and Quicke, 1998).

The centriolar adjunct, observed in these two eulophids, occurs in many insect orders including Hymenoptera. In chalcidoids, it can offer good diagnostic characters at the family and sometimes genus level. For example, in Eurytomidae (Lino-Neto et al., 1999), Trichogrammatidae (Lino-Neto et al., 2000; Lino-Neto and Dolder, 2001 ) and Eulophidae (Brito et al., 2009) this structure overlapping only the centriole region (about $0.5 \mu \mathrm{m}$ ). However, in Eurytomidae it overlaps the nucleus by a much larger distance (about $8 \mu \mathrm{m}$ ) than in Eulophidae and Trichogrammatidae (less than $0.5 \mu \mathrm{m}$ ). In the Agaonidae, Pegoscapus (Fiorillo et al., 2008) and Idarnes (Silva, 2010), the centriolar adjunct does not overlap the nucleus. 


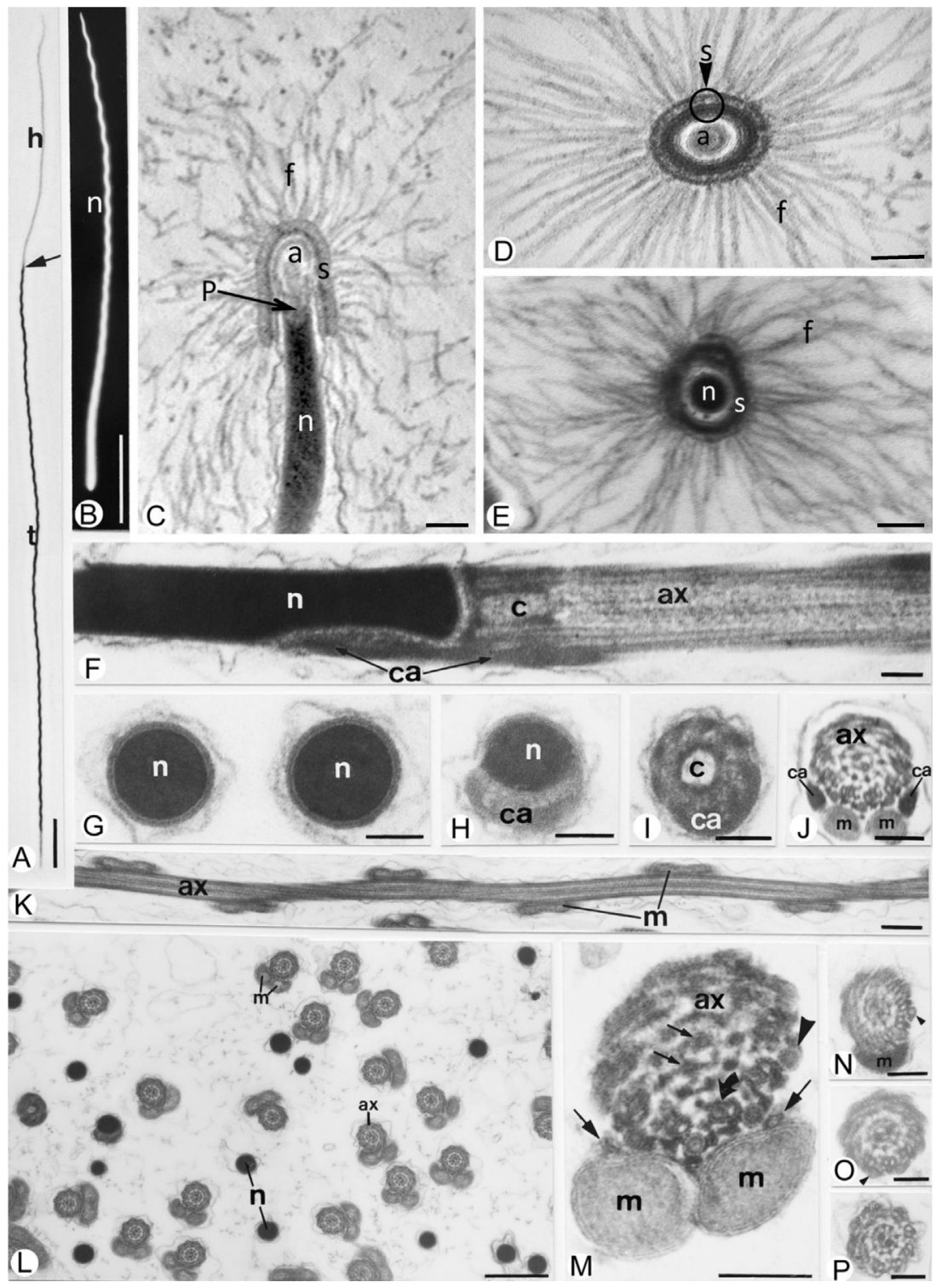

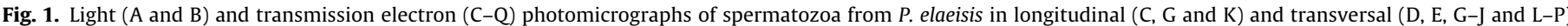

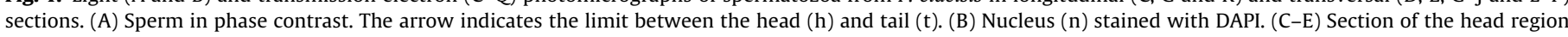

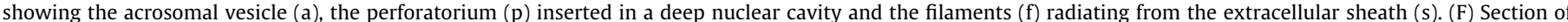

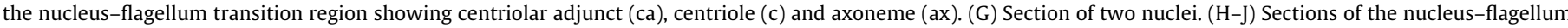

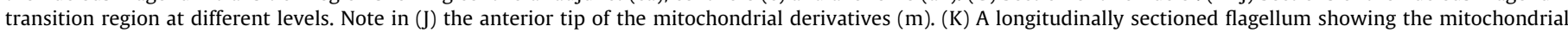

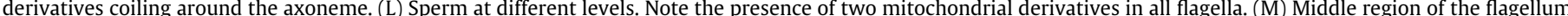

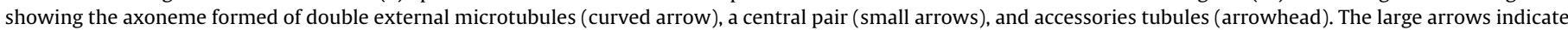

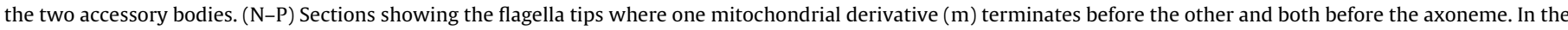
latter, the accessory microtubules (arrowheads) are first to finish. Bars: A and B $=10 \mu \mathrm{m} ; \mathrm{C}-\mathrm{J}$ and $\mathrm{M}-\mathrm{P}=0.1 \mu \mathrm{m} ; \mathrm{K}$ and $\mathrm{L}=0.5 \mu \mathrm{m}$.

It overlaps only the centriole region in Pegoscapus, but in Idarnes it runs parallel to mitochondrial derivatives by at least $4 \mu \mathrm{m}$.

Although the axoneme with $9+9+2$ microtubules is observed in many insects, changes in this pattern are commonly observed, which may represent important characters for systematics of these organisms. For example, transverse striations along the center of the axoneme, as occur in $T$. diatraeae, have never been observed in any other Hymenoptera including chalcidoids, this striations may constitute a unique characteristic for the species or genus. However, whether these striations are modifications of one existing flagellar components as the central sheath, and how they combine with other elements in the central region of the axoneme, are issues that need further investigation.

In most chalcidoids, including these two species, accessory microtubules are the first to finish, followed by the central pair and the peripheral double. However, in Pegoscapus (Fiorillo et al. 2008), the central pair is the first to end. The last peripheral double ending differentiates chalcidoids as well as two ichneumonids species (Moreira et al., 2010), of the Aculeata, in which the last to finish are accessory microtubules (see Zama et al., 2005).

In these two eulophid species, the mitochondrial derivatives, in cross-section, are symmetrical, slightly oval and smaller than, and very closed to, axoneme. These same features are the same ones showed in Eurytomidae (Lino-Neto et al., 1999) and Trichogrammatidae (Lino-Neto et al., 2000; Lino-Neto and Dolder, 2001), indicating that these three families are closely related. However, mitochondrial derivatives of $M$. hawaiiensis and $M$. australica (Brito et al., 2009) are asymmetric, possibly representing a unique characteristic for this eulophid genus. In Pegoscapus (Fiorillo et al., 2008), derivatives differ from those of the three families mentioned 


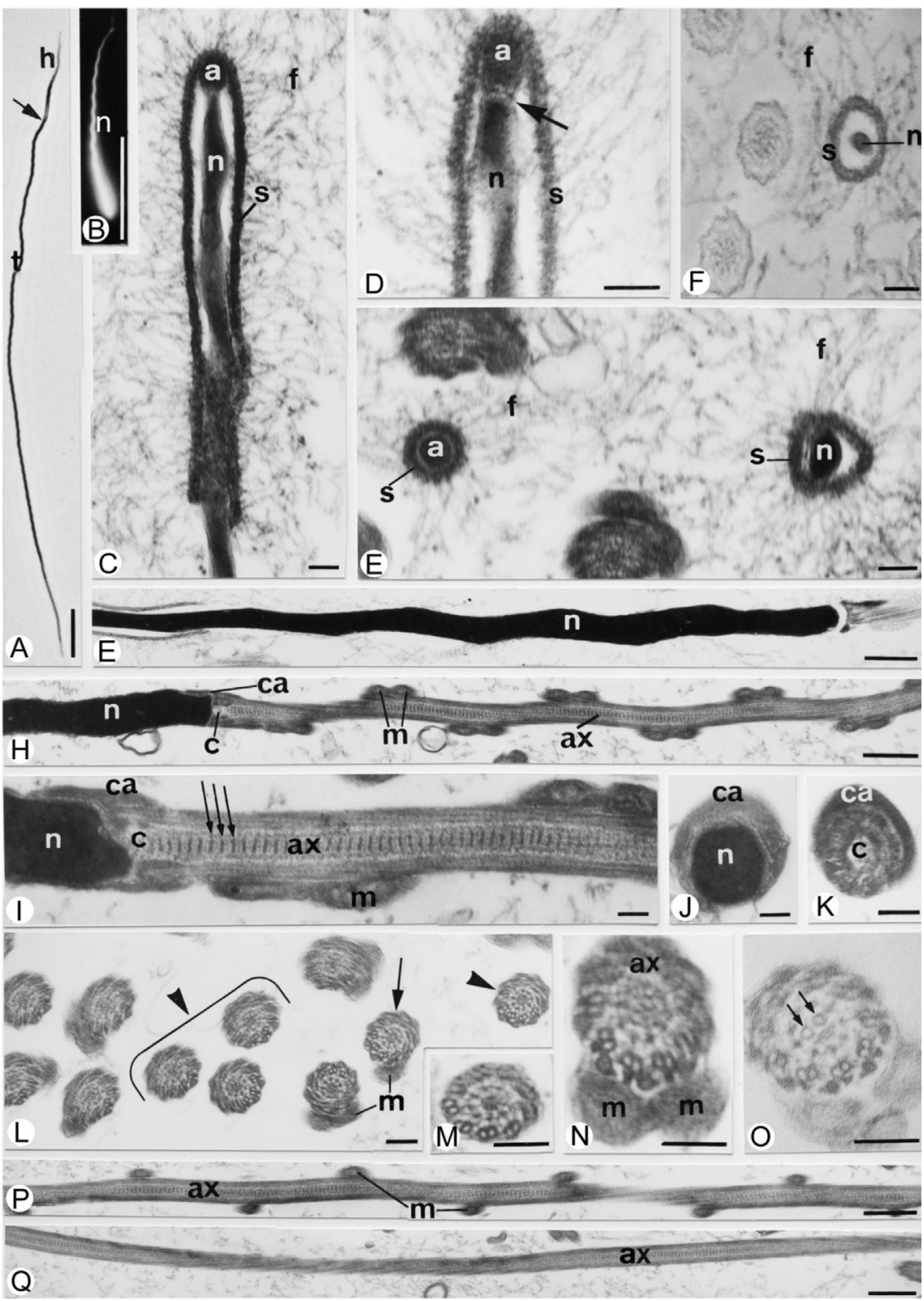

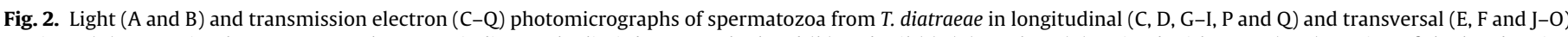

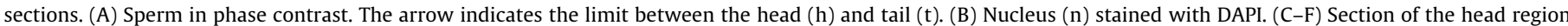

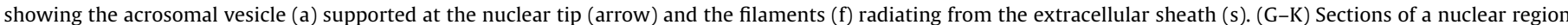

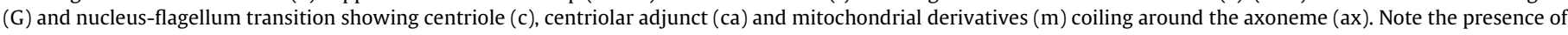

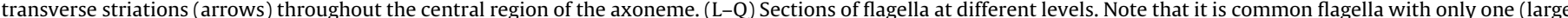

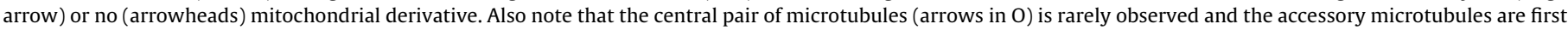
to finish (M). Bars: $A$ and $B=10 \mu \mathrm{m} ; \mathrm{C}-\mathrm{F}$ and $\mathrm{I}-\mathrm{O}=0.1 \mu \mathrm{m} ; \mathrm{G}, \mathrm{H}, \mathrm{P}$ and $\mathrm{Q}=0.5 \mu \mathrm{m}$.

above only by being slightly asymmetrical. In Idarnes (Silva, 2010), they are larger in diameter and completely surrounded by the axoneme, indicating that these two agaonid genera are distantly related.

Accessory bodies are very reduced (as in P. elaeisis) or possibly absent in some species (as in T. diatraeae), characteristics that differentiate chalcidoids from most Hymenoptera (Zama et al., 2005; Araújo et al., 2009; Moreira et al., 2012).

In conclusion, the morphological characteristics of chalcidoid sperm indicate that Eulophidae is closely related to Trichogrammatidae, as was observed by Heraty et al. (2012), and both of these families are closer to Eurytomidae than Agaonidae. In Agaonidae, Pegoscapus sperm are more similar to those three families above than Idarnes.

\section{Acknowledgments}

The authors thank the Nucleus of Electron Microscopy and Microanalysis of the UFV, Electron Microscopy Centers of the UNICAMP and the University of Brasillia (UNB), and the two anonymous reviewers who provide valuable feedback on the manuscript. This research was supported by CAPES, CNPq and FAPEMIG.

\section{References}

Araújo, V.A., Moreira, J., Lino-Neto, J., 2009. Structure and ultrastructure of the spermatozoa of Trypoxylon (Trypargilum) albitarse Fabricius 1804 (Hymenoptera: Apoidea: Crabronidae). Micron 40, 719-723. 
Brito, P., Lino-Neto, J., Dolder, H., 2009. Sperm structure and ultrastructure of the Melittobia hawaiiensis, Perkins and M. australica, Girault (Chalcidoidea: Eulophidae). Tissue Cell 41, 113-117.

Carcupino, M., Profili, G., Kathirithamby, J., Mazzini, M., 1995. Sperm ultrastructure of Xenos vesparum (Rossi) and its significance in the taxonomy and phylogeny of Strepsiptera (Insecta). Mem. Mus. Natl. Hist. Nat. 166, 291-296.

Dallai, R., Mercati, D., Carapelli, A., Nardi, F., Machida, R., Sekiya, K., Frati, F., 2011 Sperm accessory microtubules suggest the placement of Diplura as the sistergroup of Insecta S.S. Arthropod Struct. Dev. 40, 77-92.

Dallai, R., Afzelius, B.A., 1995. Phylogeny significance of axonemal ultrastructure: examples from Diptera and Trichoptera. Mem. Mus. Natl. Hist. Nat. 166 301-310.

Fiorillo, B.S., Lino-Neto, J., Báo, S.N., 2008. Structural and ultrastructural characterization of male reproductive tracts and spermatozoa in fig wasps of the genus Pegoscapus (Hymenoptera, Chalcidoidea). Micron 39, 1271-1280.

Gottardo, M., Mercati, D., Dallai, R., 2012. The spermatogenesis and sperm structure of Timema poppensis (Insecta: Phasmatodea). Zoomorphologie 131, 209-223.

Greathead, D.J., 1986. Parasitoids in classical biological control. In: Waage, J., Greathead, D.J. (Eds.), Insect Parasitoids. Academic Press, London, pp. 289-318.

Grissel, E.E., Schauff, M.E., 1997. Chalcidoidea. In: Gibson, G.A.P., Huber, J.T., Woolley, J.B. (Eds.), Annotated Keys to the Genera of Nearctic Chalcidoidea (Hymenoptera). NRC Research Press, Ottawa, ON, Canada, pp. 45-116.

Heraty, J., Woolley, J., Darling, D.C., 1997. Phylogenetic implications of the mesofurca in Chalcidoidea (Hymenoptera), with emphasis on Aphelinidae. Syst. Entomol. $22,45-65$.

Heraty, M.J., Burks, R.A., Cruaud, A., Gibson, G.A.P., Liljeblad, J., Munro, J., Rasplus, J.Y., Delvare, G., Janšta, P., Gumovsky, A., Huber, J., Woolley, J.B., Krogmann, L., Heydon, S., Polaszek, A., Schmidt, S., Darling, D.C., Gates, M.W., Mottern, J., Murray, E., Molin, A.D., Triapitsyn, S., Baur, H., Pinto, J.D., Noort, S.V., George, J., Yoder, M., 2012. A phylogenetic analysis of the megadiverse Chalcidoidea (Hymenoptera). Cladistics, 1-77.

Jamieson, B.G.M., 1987. The Ultrastructure and Phylogeny of Insect Spermatozoa. Cambridge University Press, Cambridge.

LaSalle, J., Gauld, I.D., 1991. Parasitic Hymenoptera and the biodiversity crisis. Redia 74, 315-334.
Lino-Neto, J., Dolder, H., 2001. Redescription of sperm structure and ultrastructure of Trichogramma dendrolimi (Hymenoptera: Chalcidoidea: Trichogrammatidae). Acta Zool. 82, 159-164.

Lino-Neto, J., Báo, S.N., Dolder, H., 1999. Structure and ultrastructure of the spermatozoa of Bephratelloides pomorum (Fabricius) (Hymenoptera Eurytomidae). Int. J. Insect. Morphol. Embryol. 28, 253-259.

Lino-Neto, J., Báo, S.N., Dolder, H., 2000. Structure and ultrastructure of the spermatozoa of the Trichogramma pretiosum Riley and Trichogramma atopovirilia Oatman and Platner (Hymenoptera: Trichogrammatidae). Acta Zool. (Stockholm) 81, 205-211.

Moreira, J., Araújo, V.A., Báo, S.N., Lino-Neto, J., 2010. Structural and ultrastructural characteristics of male reproductive tract and spermatozoa in two Cryptinae species (Hymenoptera: Ichneumonidae). Micron 41, 187-192.

Moreira, J., Brito, P., Mancini, K., Dolder, H., Lino-Neto, J., 2012. The descriptions of new microanatomical structure of the male reproductive system and sperm of Myschocyttarus cassununga (Hymenoptera: Vespidae). Micron 43, 292-297.

Munro, J.B., Heraty, J.M., Burks, R.A., Hawks, D., Mottern, J., Cruaud, A., Rasplus, J., Jansta, P., 2011. A molecular phylogeny of the Chalcidoidea (Hymenoptera). Plos One 6 (11), e27023.

Neumann, G., Follett, P.A., Hollingsworth, R.G., León, J.H., 2010. High host specificity in Encarsia diaspidicola (Hymenoptera: Aphelinidae), a biological contro candidate against the white peach scale in Hawaii. Biol. Control 54, 107-113.

Newman, T.M., Quicke, D.L.J., 1998. Sperm development in the imaginal testes of Aleiodes coxalis (Hymenoptera: Braconidae: Rogadinae). J. Hym. Res. 7, 25-37.

Polaszek, A., Rugman-Jones, R.S., Hernandez-Suarez, E., Cabello, T., Pérez, M.P., 2012 Molecular and morphological diagnoses of five species of Trichogramma: biological control agents of Chrysodeixis chalcites (Lepidoptera: Noctuidae) and Tuta absoluta (Lepidoptera: Gelechiidae) in the Canary Islands. Biol. Control 57, 21-35.

Quicke, D.L.J., Ingram, S.N., Baillie, H.S., Gaitens, P.V., 1992. Sperm structure and ultrastructure in the Hymenoptera (Insecta). Zool. Scr. 21, 381-402.

Silva, J.S., 2012. Caracterização ultraestrutural dos espermatozóides de três espécies do gênero Idarnes. Universidade de Brasília, Brasília, 47 f., il. Dissertação (Mestrado em Biologia Animal) (accessed 30.11.12).

Zama, U., Lino-Neto, J., Mello, S.M., Campos, L.A.O., Dolder, H., 2005. Ultrastructural characterization of spermatozoa in euglossine bees (Hymenoptera, Apidae, Apinae). Insect. Soc. 52, 1-10. 